\begin{tabular}{|c|c|c|}
\hline $\begin{array}{c}\text { 息有 } \\
\text { PUCRS }\end{array}$ & $\begin{array}{l}\text { ESCOLA DE } \\
\text { HUMANIDADES }\end{array}$ & $\begin{array}{l}\text { Revista de Filosofia da PUCRS } \\
\text { Veritas, Porto Alegre, v. } 65 \text {, n. 1, p. 1-9, jan.-mar. } 2020 \\
\text { e-ISSN: } 1984-6746 \text { | ISSN-L: 0042-3955 }\end{array}$ \\
\hline dê $h t t p: / / d x$ & org/10.15448/1984-6746.2020.1.35910 & \\
\hline
\end{tabular}

SEÇÃO: VARIA

\title{
A concepção filosófica da história em ato e suas categorias fundamentais
}

\author{
The philosophical conception of history in act and its main categories \\ La concepción filosófica de la historia en acto y sus categorias fundamentales
}

\author{
Inácio Helfer ${ }^{1}$ \\ orcid.org/0000-0001-6809-9009 \\ inahelfer@gmail.com
}

\section{Polyana Tidre ${ }^{1}$}

orcid.org/0000-0003-0144-2284

polyanatidre@gmail.com

Recebido em: 8 out. 2019.

Aprovado em: 30 jan. 2020.

Pulbicado em: 12 mai. 2020.
Resumo: Neste artigo propomos fazer uma breve reconstrução da concepção filosófica da história em Hegel a fim de podermos apresentar os aspectos determinantes através dos quais, para o filósofo, a história se exibiria ao pensamento, bem como expor seu entendimento da história em ato. Para além das categorias "passado", "presente" e "futuro", Hegel, à maneira dos Iluministas e de sua aproximação entre história e progresso ou perfectibilidade, oferece um entendimento da história como "progresso na consciência da liberdade". Analisaremos em que consiste essa definição e, ao fazê-lo, buscaremos reunir argumentos contra uma interpretação determinista da concepção hegeliana da história. Em um segundo momento, mostraremos que, se Hegel apoia uma filosofia da história e social na qual a liberdade exerce um papel fundamental, ele está, porém, interessado em combater uma noção demasiado negativa ou subjetivista da liberdade, a partir da qual o outro é visto como limitador ou mesmo oposto à mesma.

Palavras-chave: Hegel. História. Liberdade. Ato. Determinismo.

Abstract: In this article we aim to reconstruct Hegel's philosophical conception of history, in order to be able to present the determinant aspects through which, to Hegel, history shows itself to thought as well as to present Hegels conception of history "in act". Beyond categories as "past", "present" and "future", Hegel, following in the Illuminists' footsteps and in the approximation they made between history and progress or perfectibility, offers an understanding of history as "the progress in the consciousness of freedom". We propose to analyze this definition of history and, this way, to find arguments against a deterministic interpretation of Hegel's conception of history. In a second moment, we show that, even if Hegel supports a philosophy of history and a social philosophy in which freedom plays a fundamental role, he is, however, interested in combating a too negative or subjectivist notion of freedom, from which the other is considered as limiting or even as opposite to it.

Keywords: Hegel. History. Freedom. Act. Determinism.

Resumen: En este artículo proponemos hacer una breve reconstrucción de la concepción filosófica de la historia en Hegel para que podamos presentar los aspectos determinantes a través de los cuales, para el filósofo, la historia se mostraría en el pensamiento, así como para exponer su comprensión de la historia en acción. Además de las categorías "passado", "presente" y "futuro", Hegel, a la manera de los Iluministas y su aproximación entre la historia y el progreso o la perfectibilidad, ofrece una comprensión de la historia como "progreso en la conciencia de la libertad". Analizaremos en qué consiste esta definición y, al hacerlo, trataremos de reunir argumentos en contra de una interpretación determinista de la concepción hegeliana de la historia. En un segundo momento. demostraremos que si Hegel apoya una filosofía de la historia y social en la que la libertad ejerce un papel fundamental, sin embargo, está interesado en combatir una noción excesivamente negativa o subjetivista de la libertad, de la cual el otro es visto como un limitador o incluso opuesto a él.

Palabras clave: Hegel. Historia. Libertad. actuar. Determinismo. 


\section{A concepção hegeliana de história}

Quais as principais categorias da concepção filosófica de história segundo Hegel? Em que sentido essa concepção histórica tem de ser entendida? 0 que ela nos autoriza a pensar sobre as três dimensões fundamentais do tempo, a saber, passado, presente e futuro? Para podermos oferecer uma resposta a contento a essas questões, propomos uma análise dos manuscritos e anotações reunidos nas Vorlesungen publicadas por Eduard Gans a partir dos cursos de Filosofia da História oferecidos por Hegel durante a década de 1820 em Berlim. ${ }^{2}$

Nesses, Hegel apresenta uma crítica da representação corrente da história de sua época, tal como formulada pelo senso comum. Tal apercepção é comumente descrita como "um terrivel quadro (ungeheures Gemälde) feito de acontecimentos e de ações", "uma mistura a mais bizarra que nos possa parecer" (VG, p. 34. tradução nossa). Na perspectiva kantiana, ela é referida como uma exposição "abderitista" da história, pois a mesma enfatiza a alternância sem fim de progresso e de regressão, finalmente, um processo absurdo (KANT, 1993, p. 97-98)3.

Para Hegel, por sua parte, seria necessário ir além da perspectiva superficial desse discurso para pôr em evidência as categorias subjacentes à história. Seria necessário tornar explícito o que se encontra implícito e que é, ao mesmo tempo, algo mais fundamental. Nesse sentido é que Hegel, nos Cursos de 1822/28, distingue a concepção filosófica da história das demais, a história original e a história refletida (VG, p. 3, tradução nossa). Para ele, a história filosófica não deveria se ater às particularidades, mas ao universal, àquilo que resta ante o movimento incessante de nascimento, florescimento e perecimento de individuos, de povos e de Estados. Na realidade, o objeto da história filosófica é "o objeto o mais concreto, aquele que contém em si a totalidade dos diversos aspectos da existência: o indivíduo sobre o qual ela trata é o Espírito do Mundo (Weltgeist)." (VG, p. 33, tradução nossa) É assim que nos Cursos pode-se ler que a observação filosófica não teria outro propósito senão a de remoção do contingente (VG, p. 29, tradução nossa) ou de apreensão da multidão das particularidades em sua unidade ou totalidade (VG, p. 32-33, tradução nossa). É por isso que Hegel insiste no fato de que o primeiro em uma abordagem filosófica da história não é o "destino" (die Schicksale), as "paixões" (Leidenschaften), a "energia" (Die Energie) dos povos, mas o primeiro é o "espírito mesmo dos acontecimentos", o "espírito que os produziu" que consiste no "Merkur, der Führer der Völker" (VG, p. 33, tradução nossa).

Através dos Cursos põe-se em evidência, sobretudo, a existência de determinadas categorias através das quais a história se exibe ao pensamento, que se atém, assim, ao essencial, ao "importante e em si significativo" (VG, p. 35, tradução nossa)4. A primeira categoria consistiriajustamente na categoria da mudança (VG, p. 34, tradução nossa)5, isto é, na apreensão da história como uma incessante sucessão de acontecimentos onde "tudo parece perecer e nada permanecer" (VG, p. 35, tradução nossa). Assim, o perecer ou desaparecer (Vergehen) é uma noção essencial a essa categoria, que se traduz pela caducidade inerente à história: tudo tende a não mais existir, projetos políticos, constituições e mesmo povos inteiros. É posta em evidência a perspectiva pessimista da história como declínio ou destino destruidor. A caducidade dos impérios somente provoca nossa tristeza, "o dolo (Trauer) desinteressado inspirado pelo declinio de uma vida humana brilhante e civilizada" (VG, p. 35, tradução nossa).

A segunda categoria através da qual o entendimento apreenderia a história seria a

\footnotetext{
Empregaremos a sigla "VG" ao nos referirmos à edição da Filosofia da História publicada pela editora alemã Meiner (HEGEL, Georg Wilhelm Friedrich. Die Vernunft in der Geschichte. Hg. v. Johannes Hoffmeister. 6. Aufl. Hamburg: Meiner, 1994), fazendo nossa própria tradução para o português e remetendo a outras edições quando pertinente.

3 Sobre a critica de Kant à concepção abderitista da história, cf. também Christophe Bouton (2001, p. 51).

4 É interessante notar que no livro da Doutrina do Conceito da Ciência da Lógica Hegel estrutura/expõe o seu pensamento através das categorias da universalidade, particularidade e singularidade. Tais categorias constituem mesmo o pensamento do Hegel maduro, a filosofia da história inclusive. Elas aparecem aqui de uma forma sutil. No presente artigo, entretanto, não exploraremos tal exposição. Damos prioridade ao tratamento dos termos utilizados por Hegel no seu texto, que são a "mudança", "rejuvenescimento" e "fim", explicitamente enunciados por Hegel no início dos Cursos.

5 No original, Kategorie der Veränderung. Em sua tradução das Vorlesungen para a lingua portuguesa, Artur Morão opta pelo termo "categoria da variação" (HEGEL, 1995, p. 35).
} 
categoria do renascimento ou rejuvenescimento. Nos Cursos afirma-se que a nova vida "ressurge" ou "renasce" da morte, "aus dem Tode neues Leben aufersteht", e que tal processo consistiria em um rejuvenescimento do Espírito, "Verjüngung des Geistes" (VG, p. 35, tradução nossa). A decadência de uma civilização permite ao Espírito, assim como à Fênix, de renascer eternamente em meio às cinzas para uma nova vida. No entanto, no caso do Espírito, distinguindo-se da natureza, tratar-se-ia de um rejuvenescimento elevado ou transfigurado (VG, p. 35, tradução nossa) ${ }^{6}$, no qual ele "surge contra si mesmo, consome a forma de sua configuração e eleva-se assim a uma nova formação" (VG, p. 35. tradução nossa)7. Ou ainda: "O rejuvenescimento do Espírito não é um mero retorno à mesma figura. Ele é purificação (Läuterung), elaboração (Verarbeitung) de si mesmo" (VG, p. 35, tradução nossa).

Na sequência, uma terceira categoria de leitura da história se apresentaria, cuja característica consiste em revelar o "fim último" (Endzweck) da história como a realização da razão. A história em ato seria a obra secreta do espirito, cuja perspectiva a longo termo consistiria em voltar-se sobre si mesma enquanto razão, que se realiza por intermédio dos acontecimentos (VG, p. 36, tradução nossa).

Uma primeira constatação neste sucinto esboço do quadro de categorias remete ao fato de que as mudanças históricas se diferenciam das mudanças no âmbito da natureza pelo destaque dado à condição de que, no domínio do Espírito, não há propriamente uma repetição ou um simples devir, mas uma atividade que implica um fim em si mesmo como uma forma determinada de desenvolvimento (VG, p. 151. tradução nossa). ${ }^{8}$ Para pensar o curso histórico dos acontecimentos, Hegel substitui o esquema do determinismo causal, muito presente nas leituras dos historiadores da época do lluminismo, pelo modelo de um desenvolvimento orgânico associado a uma categoria mais ampla que é a cultura (Bildung). Portanto, há uma formação em curso de crescimento do entendimento sobre as razões de ser, das representações de si mesmo dos indivíduos, das ações coletivas, da política, da economia, das religiões, das artes e da filosofia. No que concerne à história, ela seria a instância na qual o espírito se cultiva progressivamente para se tornar consciente de si mesmo (nos Cursos, Hegel definirá a história universal como "o progresso na consciência da liberdade" (VG, p. 63, tradução nossa). ${ }^{9}$ Na história tratar-se-ia de uma ampliação da compreensão e da tradução fática do que seja ser livre, sobretudo no domínio institucional, organizacional e performativo da liberdade. Diz Hegel, simplificando o conjunto de suas asserções, que "um dos conhecimentos que oferece a filosofia especulativa é que a liberdade é a única verdade do Espírito" (VG, p. 55, tradução nossa).

Nesse contexto, através dos Cursos, pode-se constatar o notório apelo de Hegel a conceitos de origem aristotélica. Para Hegel, a essência do espírito é ser atividade e se manifestar enquanto tal nos atos. "O Espírito é somente o que ele faz, e ele se faz o que ele é em si" (VG, p. 151, tradução nossa). Essa atividade é "movimento infinito, energia, enteléquia" (VG, p. 161, tradução nossa). Ainda nos Cursos, dessa vez em referência explicita a Aristóteles ${ }^{10}$, Hegel defende o ponto de vista de que, no início, as determinações existem somente sob a forma de possibilidades, estão em germe, como potência, para, em seguida, serem realizadas, atualizadas para si, ou seja, realiza-se para si o que no inicio era apenas em si (VG, p. 157). ${ }^{11}$

\footnotetext{
6 Nas Vorlesungen emprega-se os termos "erhöht" e "verklärt".

"Er tritt freilich gegen sich selbst auf, verzehrt die Form seiner Gestaltung und erhebt sich so zu neuer Bildung".

Maria Rodrigues e Hans Harden traduzem o termo "Entwicklung" como "evolução" (HEGEL, 1999, p. 53).

Die Weltgeschichte ist der Fortschritt im Bewusstsein der Freiheit",

10 A questão do começo do pensar e do ser em Hegel, contudo, é diferente em relação a Aristóteles. A noção aristotélica apresenta um movimento da causa primeira, incausada, para a causa segunda. Em Hegel temos um movimento cíclico no qual causa e consequência se identificam, na interdeterminação dos componentes. O desdobramento deste tema requereria um aprofundamento num outro contexto.

11 "Hier ist nur anzumerken, daß der Geist von seiner unendlichen Möglichkeit, aber nur Möglichkeit anfängt, die seinen absoluten Gehalt als Ansich enthält, als den Zweck und das Ziel, das er nur erst in seinem Resultate erreicht, welches dann erst seine Wirklichkeit ist. - So erscheint in der Existenz der Fortgang als von dem Unvollkommnen zum Vollkommenern fortschreitend, wobei jenes nicht in der Abstraktion nur [als] das Unvollkommene zu fassen ist, sondern als ein solches, das zugleich das Gegenteil seiner selbst, das sogennante Vollkommene, als Keim, als Trieb in sich hat: wie die Möglichkeit wenigstens reflektierterweise auf ein solches selbst hindeutet, das wirklich werden soll, und näher die aristotelische dynamis auch potentia. Kraft und Macht ist. Das Unvollkommene so als das Gegenteil seiner in ihm selbst ist der Widerspruch, der wohl existiert, aber der Impuls des geistigen Lebens in sich selbst, e) die Rinde der Natürlichkeit, Sinnlichkeit, der Fremdheit seiner selbst zu durchbrechen und zum Lichte des Bewußtseins, d. i. zu sich selbst, zu kommen" (grifo do autor).
} 
Em relação à história, essa compreensão implica que, na trama dos acontecimentos nos quais o Espírito se cultiva, não se pode aceitar que suas determinações venham de fora, do exterior. Pelo contrário, elas são oriundas do lento processo de cultivo interior do Espírito, fruto de uma maturação que preside sua formação concreta. Nos Cursos de 1827-1828 Hegel explica que o

Espirito se torna para si um objeto. No entanto, enquanto ele é para nós, mas ainda não se conheceu a si mesmo, ele ainda não é seu objeto segundo sua verdadeira forma. Seu fim é, entretanto, tornar-se consciente de que ele próprio aspira somente a conhecer como ele é em si e para si mesmo, que ele se manifesta a si mesmo na sua verdade [...] (VG, p. 61).

O desenvolvimento do Espírito não é, contudo, como já se via na exposição da segunda categoria da história, do renascimento ou rejuvenescimento, "uma simples eclosão sem direção e luta, como na vida orgânica, mas um trabalho duro e forçado sobre si-mesmo" (VG, p. 152, tradução nossa). O grau mais elevado da vida do Espírito se manifesta pelo fato de ele possuir uma dimensão reflexiva porque "a passagem de sua determinação à sua realização é mediatizada pela consciência e a vontade" (VG, p. 151, tradução nossa). Enquanto - Espírito não alcança essa condição, por exemplo, em um povo determinado no qual experimenta uma "realidade inorgânica de Espírito", "inconsciente da liberdade", "do bem e do mal", "das leis" (VG, p. 162, tradução nossa), ele não vislumbra a possibilidade de evoluir em direção à liberdade. O grande aporte de Hegel a esse ponto de vista consiste em defender que aquilo que o espírito é em si pode ser atualizado somente por intermédio de sua vontade livre e ação. Conforme Bouton (2001, p. 53), "o que o Espírito é em potência, em si, somente uma vontade livre pode o realizar"; por isso, na configuração do que seja uma vontade livre, conforme enfatiza Bouton, importa considerar que:

isto significa que as possibilidades que ele [o Espírito] tem em si são reais na medida em que elas correm o risco do insucesso e requerem, para serem realizadas, individuos concretos que estejam 'no ápice' de todas as ações históricas.
O papel da liberdade se revela criador se é verdadeiro que no caso do homem a atualização do em si não é o simples desenvolvimento do que está já presente nele, mas igualmente sua transformação, que lhe aporta uma determinação inteiramente nova (2001, p. 53).

É nesse sentido que Hegel faz uma distinção entre Espírito e Natureza: no tocante à história, terreno do Espírito, não há, como na imagem da Fênix, um "eterno retorno", uma repetição enfadonha, tediosa, monótona (langweilig), porque previsivel, de algo que, renascendo das cinzas, seria sempre igual à sua figura anterior, e no fim de seu desenvolvimento, sempre igual a seu começo. As transformações na natureza, apesar de sua diversidade infinita, mostram apenas um ciclo que sempre se repete; na natureza não se dá nada de novo sob o Sol, e neste sentido o jogo tão multiforme de suas configurações acarreta uma monotonia consigo (VG, p. 149, tradução nossa). O "teatro" (VG, p. 53, tradução nossa) da história seria, ao contrário, caracterizado incessantemente pelo nascimento, florescimento e decadência do Espírito de povos determinados, dando lugar não a um Espírito idêntico ao anterior, mas superior ou mais elevado, desenvolvido através de um processo de suprassunção ou Aufhebung.

Portanto, Hegel assinala uma separação muito clara entre o devir da vida orgânica animal, privada de liberdade, e o movimento criador do espírito, entre o tempo natural, repetitivo, e o tempo histórico. Essa diferenciação, como assinala Bouton, "é decisiva" na analítica histórica hegeliana, uma vez que ela

permite compreender o lugar essencial que a liberdade humana ocupa no processo histórico e põe as balizas de uma concepção aberta de história. Antes de ser o fim, a liberdade é o princípio motor da história, ela é o que realiza a atualização do ser em potência do espirito no curso do seu desenvolvimento, a mediação irredutivel situada entre o espirito existindo em si e sua realização (2001, p. 53).

Há, contudo, interpretações que contestam esse ponto de vista, a exemplo da crítica feita por Karl Popper (1974) ou, mais recentemente, Axel Honneth (2017), a Hegel. Popper assinala 
que a filosofia da história de Hegel faz coro às "interpretações historicistas" (1974, p. 277) na medida em que a história estaria imbuida ai de uma necessidade imperiosa ${ }^{12}$. Honneth, por sua vez, em A ideia de socialismo, afirma que, para Hegel, a liberdade não dependeria da subjetividade, "de um processo individual de análise moral das máximas", tal como em Kant, mas sim da satisfação de necessidades "correspondentes a determinada fase histórica da razão" (2017, p. 39). Mais à frente, ele imputa à concepção hegeliana de história a noção de inevitabilidade, quando afirma que Proudhon, sob influência da filosofia da história de Hegel, "quis compreender o socialismo que apregoava como caracteristica de uma ordem social futura para a qual a evolução histórica seria impelida com a inevitabilidade de uma lei comprovável" (HONNETH, 2017, p. 66-67).

A nosso ver, essas críticas obliteram, contudo, a ênfase hegeliana dada à questão da liberdade. da contingência e da atividade criadora que todo o espírito de um povo tem para si como desafio na superação das contradições e na ampliação do progresso da consciência da liberdade.

\section{A liberdade e o perigo do subjetivismo}

É no intuito de valorizar a importância da liberdade que Hegel afirma, nos Cursos, insistindo na distinção entre Espírito e Natureza: "Esse fenômeno do espiritual mostra, de maneira geral, no caso do homem, uma determinação diferente da dos objetos naturais [...], uma capacidade real de transformação, e para melhor - um impulso de perfectibilidade" (VG, p. 149, tradução nossa). Estabelecer que o que determina o indivíduo é um "impulso da perfectibilidade" equivale a negar que não se trata de uma determinação já posta no início, positiva, daquilo que o indivíduo tem de se tornar, mas o que o determina está em aberto. O fim do Espírito, já contido "em si", consiste em ser livre (HEGEL, 1995. p. 52) ${ }^{13}$, mas essa determinação é justamente uma que não o é enquanto determinação já acabada, externa ou cega.

Essa visão, compartilhada pelos iluministas, de que o homem é imbuido pela busca de perfectibilidade ${ }^{14}$, se encontra de maneira paradigmática em Rousseau. Em 1755, em seu Discurso sobre a origem das desigualdades entre os homens, Rousseau identifica a capacidade à perfectibilidade, assim como a liberdade, como características essenciais do homem. O animal, ao contrário do homem, comandado inteiramente por seus instintos, "se torna em alguns meses aquilo que ele será por toda a sua vida", "cujo gênero continuará a ser, depois de milhares de anos, aquilo que o era no início" (ROUSSEAU, 1995, p. 105-109). No entanto, para Rousseau, em uma posição consequente à crítica à civilização presente em seus dois Discursos, a capacidade humana à perfectibilidade é vista de maneira extremamente negativa, como "fonte de toda infelicidade do homem" (1995, p. 109). Se afastando de um estado de natureza no qual sua independência em relação aos outros possibilitaria ao homem uma vida autônoma, ele se torna, através da vida em comunidade, cada vez mais escravo de "necessidades criadas", surgidas através do avanço das ciências e técnicas, em um processo civilizatório marcado, ao mesmo tempo e contraditoriamente, por um luxo e uma pobreza crescentes (ROUSSEAU, 1995).

Essa forte desconfiança de Rousseau em relação ao processo civilizatório é radicalmente oposta à posição de Hegel. No parágrafo 187 de sua Filosofia do Direito, ao declarar que o processo de saida (Hinausgehen) da imediatidade naturalé o fim da razão (GW 14,1, § 187. Anotações), Hegel se coloca abertamente contra Rousseau, o qual, para Hegel, veria a Bildung como "algo somente exterior, pertencente à corrupção ou ao vício (Verderben)" (GW 14,1, § 187, Anotações). ${ }^{15}$

\footnotetext{
12 Segundo Popper, "o historicismo empenha-se em encontrar o Caminho pelo qual a humanidade está fadada a marchar, empenha-se em descobrir a Chave da História (como diz J. Macmurray) ou a Significação da História" (1974, p. 277). Popper também vincula Hegel ao "historicismo teístico" (1974, p. 280).

13 Ideia de liberdade humana.

14 Ver os ensaios de Lessing. Herder e Mendelssohn em torno da definição do esclarecimento (BAHR (Ed.), 1974).

15 Cf. também o primeiro discurso de Rousseau, Discurso sobre as ciências e as artes (ROUSSEAU, 1995, p. 15): "In dem Maß, in dem unsere Wissenschaften und Künste zur Vollkommenheit fortschritten, sind unsere Seelen verderbt geworden."
} 
Na Filosofia da História, Hegel, combatendo não só Rousseau, mas também os jusnaturalistas, critica a ideia de que o homem seria livre e possessor de direitos em um estado de natureza, anterior à instauração de qualquer instituição ética, e que ele deveria restringir sua liberdade natural ao adentrar na vida em sociedade sob a proteção do Estado. Para Hegel, ao contrário, o homem, em sua existência puramente natural e imediata, padeceria da falta de liberdade e de direitos. Para ele, de acordo com o parágrafo § 187. a liberdade não é algo de imediato e natural. Ela deve ser conquistada através da intervenção da disciplina do saber e do querer, dependendo necessariamente do "outro" - não só do outro como aqueles dos quais o indivíduo é dependente para a realização da própria liberdade, mas também como instituições, cuja figura central é o Estado. Para Hegel, portanto, a única "limitação" imposta pelo Estado e pela sociedade seria direcionada não contra a verdadeira liberdade, mas contra os impulsos grosseiros, os sentimentos obtusos ou os caprichos do arbitrio (HEGEL, 1995, p. 100-102).

Contrariamente às coisas naturais, desprovidas de conceito, o domínio do Espírito é aquele no qual os individuos tornam-se conscientes daquilo que os determina de forma mais imediata (por exemplo, a necessidade biológica de se alimentar), tornando-se capazes, através do harte Arbeit der Bildung, se não de se libertarem completamente dessas determinações, ao menos de forjarem meios que tornem possivel o domínio sobre as necessidades a serem satisfeitas, e mesmo a elaboração de novas necessidades. Para se alimentar, os indivíduos não precisam ficar totalmente submissos à natureza, tendo de se conformar aos ciclos e ao ritmo desta última, mas podem cultivar a terra, criar máquinas para a colheita, construir depósitos e organizar meios de transporte para disponibilizar o alimento em regiões distantes, processá-lo etc., de maneira que, ainda que não possam se libertar da necessidade natural de comer, podem, contudo, ter maior autonomia para decidir o que, quando, onde e como satisfazer tal necessidade, obtendo desse modo um tempo e energia maiores para se dedicarem à satisfação de outras necessidades.

Assim, a liberdade depende, para Hegel, de um processo de formação ou, para retomar o registro dos iluministas, de um processo de aperfeiçoamento. Mas, distintamente da concepção rousseauniana, tal processo é visto positivamente ante a imediatidade natural e. especialmente para Hegel, ante a visão abstrata de um indivíduo existindo isoladamente. O que determina o indivíduo de maneira mais essencialé justamente, como o defende Kant, sua capacidade de autodeterminação, de agir segundo as leis que ele mesmo se dá. Com isso, aliás, pode-se combater aqueles que interpretam a concepção histórica de Hegel como determinista: de um processo necessário se desenrolando sem a participação ativa dos indivíduos, de modo independente ante sua vontade e atividade. ${ }^{16}$

Mas, ao mesmo tempo em que Hegel concorda com a posição kantiana, ele também antevê nas bases postas por Kant uma brecha perigosa a um entendimento nocivo da relação entre indivíduo e sociedade, a qual negligenciaria o papel essencial do todo ético (costumes, leis, instituições do Estado moderno) como condição de possibilidade para a efetivação da vontade livre.

Kant, é verdade, é consciente da importância da obediência, pelo sujeito, daquilo que é decidido pelo monarca e pelo governo. Em "Was ist Aufklärung?", artigo publicado em 1874 pela Berlinische Monatsschrift, reagindo à questão de Zöllner sobre o que seria "esclarecimento" e à sua crítica da Aufklärung como uma corrente que procuraria enfraquecer os fundamentos da moralidade e o valor da religião, Kant - assim como o fazem Mendelssohn e Herder - se esforça em defender a necessidade de uma harmonia na relação entre os deveres do "homem" e aqueles do "cidadão".

16 Essa interpretação inspira teóricos das mais variadas tradições, cuja crítica a um suposto determinismo da concepção histórica de Hegel é transposto também ao âmbito político, endossando a posição sustentada originalmente por Rudolf Haym de Hegel como precursor de um modelo de Estado totalitário ou antidemocrático. Isso se aplica, por exemplo, às críticas aqui já mencionadas de Popper e Honneth Em relação à concepção política e do Estado de Hegel, Honneth afirma que ele faria "ampla abstração de todas as possibilidades de influência dos cidadãos" (2011, p. 583). A concepção hegeliana do Estado seria "centralista" e, assim, pouco apta a permitir instituições promovendo uma relação "horizontal" entre os individuos, com "pouco interesse na real capacitação para a democracia" (HONNETH, 2011, p. 485). 
Ao mesmo tempo em que faz uma distinção entre uso público e uso privado do entendimento, Kant destaca a importância da capacidade de se assumir um "comportamento meramente passivo", orientado, através do "consenso artificial do governo", à perseguição de fins públicos.

Para alguns negócios que se exercem
no interesse da comunidade é neces-
sário um certo mecanismo, por meio
do qual alguns membros da comuni-
dade devem comportar-se de modo
exclusivamente passivo, para serem
conduzidos pelo governo através de
uma unanimidade artificial para fina-
lidades públicas [...]. Em casos tais, de
fato, não é permitido raciocinar, mas
deve-se obedecer (KANT, 1784, S. 11).

Para ele, ainda que não se possa afirmar que seu tempo é um "tempo esclarecido", ele seria um "tempo do Esclarecimento [Zeit der Auklärung] ou o século de Frederico" (KANT, 1784, S. 15), cuja atuação é vista por Kant com otimismo.

Ao mesmo tempo, Kant defende o sapere aude!, a necessidade de que o homem seja corajoso para usar seu próprio entendimento, saindo de uma condição de menoridade (Unmündigkeit) em relação a uma autoridade externa ou cega. Essa exigência dos Iluministas, ainda que legítima, inspirará os defensores de um subjetivismo radical, que Hegel compreende como os "românticos" (PÖGGELER, 1998, p. 218). ${ }^{17}$ A tendência à subjetivização (SIEP, 2014. p. 12) será o traço comum que caracterizará as diferentes correntes e representantes desse movimento, duramente criticados por Hegel. ${ }^{18}$ É nesse sentido que Hegel critica, ainda, a influência de Jacob Fries nas associações estudantis das Burschenschaften ${ }^{19}$ : essa subjetivização levaria, em última instância, a um dualismo insuperável entre individuo e instituições éticas (SIEP, 2014, p.
12), ou ao problema do entendimento da vida em comunidade como aquela na qual as liberdades individuais seriam vistas como aleijadas ou mesmo impedidas pelo outro. ${ }^{20}$

Assim, se para Hegel a realização da liberdade é o critério decisivo acerca da racionalidade daquilo que existe, é necessário que sejamos aptos não somente a colocar em questão a validade das instituições que nos cercam, mas que, indo além, possamos reconhecer a legitimidade das instituições que cumprem as condições permitindo a efetivação da liberdade. Para que elas cumpram com essas condições são necessárias que haja nelas a preservação e o aperfeiçoamento constante de dimensões de participação de cada indivíduo como membro da comunidade. A efetivação da consciência da liberdade se dá, assim, através do crescimento da atuação de cada um nos assuntos comuns e, consequentemente, do reconhecimento auferido pelos partícipes nesse empreendimento. Desta forma, as práticas subjetivistas perdem força e ganha espaço a valorização orgânica do individuo nas instituições.

\section{Considerações finais}

A história corresponde, deste modo, a um movimento que implica destruição e nascimento segundo um desenvolvimento cujo fim é a realização do espírito. A síntese dessas categorias reside no conceito de progresso. Não um progresso em primeiro lugar das ciências, ou um progresso político, moral ou da felicidade, mas, antes, um progresso da consciência que os homens tomam de sua liberdade: "a história apresenta o desenvolvimento da consciência que o Espírito tem de sua liberdade, e da realidade produzida por esta consciência" (VG, p. 167, tradução nossa).

Contra o viés determinístico de leitura da

\footnotetext{
17 "Hegels Forderung an den Menschen ist nun, sich aus der Tiefe seiner Spontaneität heraus in dieses Ganze des Geistes hineinzustellen und aus dem allgemeinen, substantiellen Selbst heraus zu denken und zu handeln. Den Romantikern aber wirft Hegel in verschiedenen starkem Maße vor, daß sie ihre Subjektivität nicht in dieses Ganze des Geistes aufgeben und aus ihm ergreifen, sondern den Subjektivismus auf die Spitze treiben".

18 Siep faz referência, neste contexto, ao Sturm und Drang, à Empfindsamkeit e à Frühromantik, a Jacobi e seu Gefühl e Geniemoral, a Schleiermacher e sua teologia do sentimento, a Novali e sua absolutização da schöpferischen Gewissen, ou, ainda, a Schlegel e sua ironia (2014, p. 12). 19 As Burschenschaften são associações políticas assumindo um papel vanguardista especialmente no periodo entre a invasão do Sacro Império Romano-Germânico por Napoleão e a Restauração. Para uma análise do período histórico em questão, ver Engels (1972)، Knudsen (1972) e Tidre (2018)

20 Sobre a crítica de Hegel a uma concepção de liberdade meramente negativa ou moralista, ver Honneth (2015). Cf. também Helfer e Tidre (2020).
} 
história, Hegel coloca em evidência a necessidade de considerar o crescimento da consciência da liberdade. Tal consciência se manifesta, sobretudo, na perspectiva de salientar e incentivar a prática do desenvolvimento orgânico de comunidades, em seus diferentes âmbitos, o familiar, do mercado e da esfera estatal propriamente dita. Ao mesmo tempo, tal consciência se manifesta em uma medida mais ampla através da constatação e da prospecção do crescimento da cultura de um povo, em especial, e dos povos em geral.

Assim, no contexto da história, que é sempre resultante da dialética que os diferentes espíritos dos povos estabelecem entre si, a cultura (Bildung) em geral se aprimora, não como uma aposta de Hegel diante de um cenário que poderia ou não acontecer, e também não como uma certeza irremediável, mas como resultado da indicação advinda de determinações teóricas e práticas do passado e do presente que the dão convicções. É muito conhecida a tipificação hegeliana das três fases da história pelas quais a humanidade passou: o periodo em que um único homem era livre; o periodo em que alguns eram livres; e o periodo em que o homem como tal é reconhecido como livre. Ou seja, para Hegel, que ministra seus cursos sobre a filosofia da história, em seu tempo, todos os homens são reconhecidos como livres, o que não significa que, nas determinações objetivas das determinações institucionais em geral a liberdade já tenha se efetivado como tal. O que se efetivou, contra a leitura determinística da história, é o progresso na consciência da liberdade. Ela não garante deterministicamente a sua realização. Ela aponta, retomando a terceira categoria da história apresentada no início, o "fim último" para o qual se direciona o esforço da humanidade que é a realização da razão. A história em ato seria a obra secreta do espírito, cuja perspectiva a longo termo, mas, também, em cada momento histórico e espírito de um povo, consiste em voltar-se sobre si mesma enquanto razão, que se realiza por intermédio dos acontecimentos. A crença por parte de Hegel na perfectibilidade do homem e da humanidade não é uma mera aposta, nem uma certeza irremediável. É a sua convicção, ou melhor, a tradução revelada da ação do espírito que se volta sobre si e se descobre como o aprofundamento e a efetivação renovada no tempo da Bildung. Neste sentido, a história é o desenvolvimento da consciência que o espírito tem de sua liberdade e a realidade produzida por essa consciência.

\section{Referências}

BAHR, Ehrhard (ed.). Was ist Aufklärung? Thesen und Definitionen. Kant, Erhard, Hamann, Herder, Lessing, Mendelssohn, Riem, Schiller, Wieland. Stuttgart : Philipp Reclam, 1974.

BOUTON, Christophe. L'analitique de l'histoire : l'apport de Hegel dans la constitution du concept moderne de Geschichte. In: Hegel: droit, histoire. société, n. 15. Paris: PUF, 2001. p. 43-66. https://doi. org/10.4000/rgi.825

ENGELS, Friedrich. Deutsche Zustände I-III. In: Marx, K.; Engels, F.: Werke (MEW), Bd. 2. Berlin: Dietz, 1972.

HEGEL, Georg Wilhelm Friedrich. Die Vernunft in der Geschichte. Hg. v. Johannes Hoffmeister. 6. Auf. Hamburg: Meiner, 1994. (VG)

HEGEL, Georg Wilhelm Friedrich. A razão na história. Introdução à Filosofia da História Universal. Trad. Artur Morão. Lisboa: Edições 70, 1995.

HEGEL, Georg Wilhelm Friedrich. Filosofia da história. Trad. Maria Rodrigues e Hans Harden. 2. ed. Brasília: UnB, 1999

HEGEL, Georg Wilhelm Friedrich. Grundlinien der Philosophie des Rechts. In: Ders.: Gesammelte Werke, Bd. 14,1, hg. v. Klaus Grotsch u. Elisabeth Weisser-Lohmann. Hamburg: Meiner, 2009. (GW 14,1)

HELFER, Inácio; TIDRE, Polyana. "Entre Honneth e Hegel: da liberdade à eticidade em 'O direito da liberdade'". In: TRANS/FORM/AÇÃO. Marilia: UNESP, 2020 (impresso). No prelo.

HONNETH, Axel. A ideia de socialismo. Tentativa de atualização. Trad. Marian Toldy e Teresa Toldy. Lisboa: Edições 70, 2017.

HONNETH, Axel. O direito da liberdade. Trad. Saulo Krieger. São Paulo: Martins Fontes, 2015.

KANT, Immanuel. O conflito das faculdades. Lisboa: Edições 70, 1993.

KNUDSEN, Jonathan. Restauration in Berlin: Anpassung und Opposition nach 1815. In: Blänkner, R.; Göhler, G.; Waszek, N. (Hg.). Eduard Gans (1797-1839). Politischer Professor zwischen Restauration und Vormärz. Leipzig: Leipziger Universitätsverlag, 2002.

PÖGGELER, Otto. Hegels Kritik der Romantik. München: Fink, 1998.

POPPER, Karl. A sociedade aberta e seus inimigos. Trad. de Milton Amado. São Paulo: EDUSP/Itatiaia, 1974. 2v. 
ROUSSEAU, Jean-Jacques. Über Kunst und Wissenschaft. In: Kurt Weigand (Hrsg.). Schriften zur Kulturkritik/Jean-Jacques Rousseau. Über Kunst und Wissenschaft (1750), Über den Ursprung der Ungleichheit unter den Menschen (1755). 5. Auflage. Hamburg: Felix Meiner Verlag, 1995.

SIEP, Ludwig. Vernunftrecht und Rechtsgeschichte. Kontext und Konzept der Grundlinien im Blick auf die Vorrede. In: Siep, Ludwig (Hg.). G. W. F. Hegel: Grundlinien der Philosophie des Rechtes, 3. Auflage. Berlin: Akademie Verlag, 2014. https://doi. org/10.1524/9783050093536

TIDRE, Polyana. Individuum und Sittlichkeit. Die Beziehung zwischen Allgemeinheit und Besonderheit in Hegels Grundlinien der Philosophie des Rechts. Berlin: wvb, 2018.

\section{Inácio Helfer}

Doutor em Filosofia pela Université Paris 1 Pantheon-Sorbonne, professor da Universidade do Vale do Rio dos Sinos (UNISINOS), pesquisador Produtividade Pesquisa do CNPq.

\section{Polyana Tidre}

Doutora em Filosofia pela Humboldt-Universität zu Berlin, pós-doutoranda CAPES-PNPD em Filosofia na Universidade do Vale do Rio dos Sinos (UNISINOS), autora do livro "Individuum und Sittlichkeit: Die Beziehung zwischen Allgemeinheit und Besonderheit in Hegels Grundlinien der Philosophie des Rechts", publicado em 2018 pela Wissenschaftlicher Verlag Berlin.

\section{Endereço para correspondência}

Inácio Helfer

Universidade do Vale do Rio dos Sinos (UNISINOS)

Av. Unisinos, 950, Prédio Bog, sala 349

Cristo Rei, 93020-190

São Leopoldo, RS, Brasil

Polyana Tidre

Universidade do Vale do Rio dos Sinos (UNISINOS)

Av. Unisinos, 950, Prédio Bog, sala 350

Cristo Rei, 93020-190

São Leopoldo, RS, Brasil 